\title{
Operational causes of fatigue failures within passages of gas turbine engines
}

\author{
Zbigniew Korczewski, Assoc. Prof. \\ Gdansk University of Technology
}

\begin{abstract}

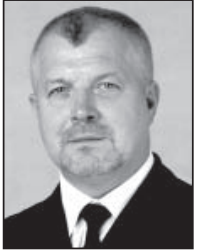

In this paper a short presentation of fatigue wear process of structural elements of gas turbine engines has been given. The primary causes of fatigue crack formation within engine mechanical system and flow passages have been highlighted. Special attention was paid to low-cycle fatigue associated with unsteady heat-and-gas-flow processes developed in the passages. The selected damages have been demonstrated of gas flow paths of the engines operating in aviation, navy and power industry, along with origins of their formation and growth.
\end{abstract}

Keywords: gas turbine engines, passages, fatigue wear, operational failures

\section{INTRODUCTION}

In the period of intensive investigations to improve operational reliability, durability and economic merits of gas turbine engines, a problem of ef fective methods of their technical state assessment becomes more and more important especially that in recent years a trend is observed of passing from the operation-based, planned maintenance to that based on current technical state, $[1,6,7]$.This is specially recommended when an unforeseen failure of engine is associated with a great hazard to traffic safety at sea, air and land [9, 14].

It is especially complicated to evaluate unserviceability states of turbine engine flow passages irrespective of an area of engine application. Technical state assessment traditionally performed on the basis of service measurements of gas-dynamic parameters does not bring satisfactory results in the case of fast developing surface defects of flow passages, which do not generate usually observable diagnostic symptoms. Service experience justifies that just most troublesome are flow passages of engine high-temperature part which is most exposed to thermal low-cycle fatigue whose consequences bring many hazards to engine safe operation. It is influenced by many factors, and the most important of them is associated with destructive and unavoidable effects of varying mechanical and thermal loads applied to elements of engines during their work in unsteady states $[2,3,14]$.

\section{LOW-CYCLE FATIGUE}

One of the parameters which impact turbine engine durability the most is fatigue strength of material of which its structure is built. During engine operation on a ship cyclic elastic and plastic deformations of structural elements take place, which result from multifold changes of mechanical loads (caused by gas forces generated by thermal dynamic cycle of engine as well as by rotary motion inertia forces of rotor units) and thermal loads (resulting from temperature gradients within structural elements). They cause variable internal stresses developing finally resulting in fatigue cracks. With a view of initial causes of fatigue failure development the following can be distinguished:

- high-cycle fatigue (mechanical), which is characteristic for engine rotating units (engine rotor units) and occurs below yield point of structural material. Fatigue failures appear after a cycle number of load changes over 10 (usually over $\left.10^{7}\right)[3,4,5,9]$;

low-cycle fatigue (thermal) which concerns the engine elements exposed to high-temperature efects due to exhaust gas flow (combustion chamber, stationary load-carrying elements of turbine part) which occurs over yield point of material. Fatigue cracks appear already below the cycle number of load changes equal to $10^{4}[3,4,5,10]$.

Relation between stress amplitude and cycle number of load changes, at which structural elements become failed due to material fatigue, is represented by the so - called Wöhler curve $[5,10]$.

High-cycle fatigue of rotating elements of turbine engine rotor units is caused by vibrations, that means resonance phenomenon to appear:

- in global sense when the entire engine suf fers vibrations and then it constitutes a problem for designers, 
- in local sense when one of the natural vibration frequencies of a given engine element, $\mathrm{f}_{0}$, appears close to the frequencies of periodically changeable vibration excitating forces, $f_{e x c}$. In this case the increasing of deformations and stress amplitudes takes place and after a longer period of engine's operation in such conditions a crack may appear in the element and its failure may happen due to material fatigue.

Maximum amplitude of resonance vibrations depends on stiffness and damping properties of supports of engine rotor units. The higher values of stifness coefficients the smaller amplitude of resonance vibrations $[1,3]$.

Loss of stability of engine mechanical system under operation results from occurrence and development of the following detrimental phenomena:

- slowly worsening unbalance state of rotor units resulting from sediments, erosion, corrosion and bent shafts;

- sudden increase of unbalance state of rotor units resulting from broken-off fragments of a rotating element, e.g. a blade;

- exceedance of allowable load of bearings;

- rotors seizing in engine body elements in labyrinth sealings,

- appearance of self-exciting vibrations of rotor blades, mainly in compressors, (so-called flutter), during steady flow of working medium [11],

- air and exhaust gas pressure pulsations within flow passages, as well as due to non-uniform distribution of temperature and flow velocity around flow passage circumference.

Mechanical resonance phenomenon is of a very great influence on engine's serviceability and durability. However especially dangerous to its reliability is thermal fatigue of structural elements of combustion chamber and turbines, as a result of occurring unsteady processes such as start-ups, load changes (accelerations and decelerations), as well as engine turn-offs from operation.

For instance, during engine' s starting-up, within a few seconds structural elements of combustion chamber are exposed to dynamic thermal loads characterized by instantaneous exhaust gas temperature increments reaching about $80 \div 90$ $\mathrm{K} / \mathrm{s}$ [16]. In the case of exceeding the allowable temperature gradients, pumping phenomenon and even that of structural material creeping and deformation of turbine blades can occur Fig. 1.

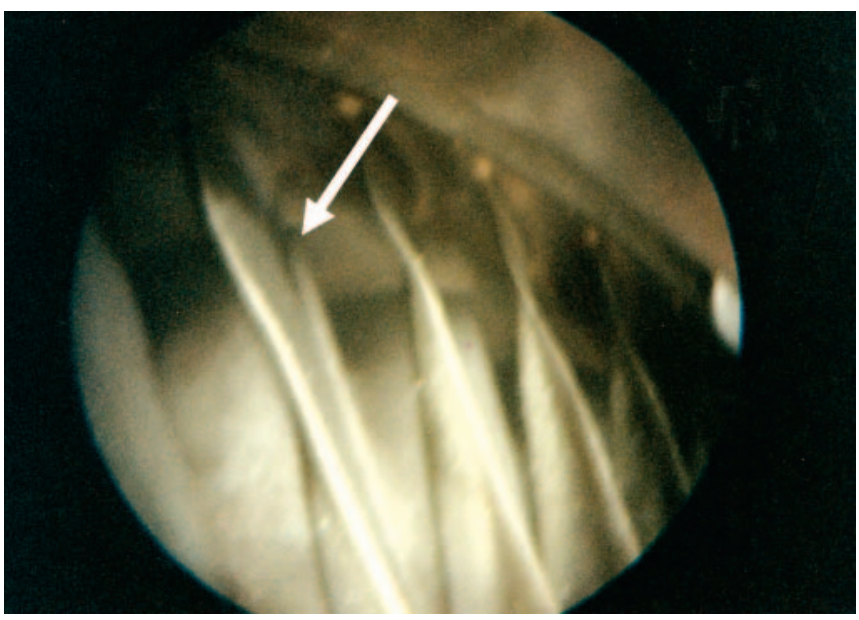

Fig. 1. Deformations of LP turbine rotor blades, resulting from structural material creeping (acc. endoscopic examination)
In extreme cases, local burning-of f edges and tips of HP turbine blades can happen, Fig. 2 and 3. Such failures of ship engine flow part usually result from sudden and unforeseeable operational events such as:

- choking the exhaust gas outflow due to fire in outlet channel,

- choking the engine air inlet (frozen air inflow shutters, sucking-in random things such as protective covers of shipboard devices etc).

And, in the case of immediate stopping the engine during its operation in nominal (or near nominal) conditions, associated with eliminating idle running cooling phase, rotor seizure in turbine body may happen, Fig. 4 and 5 .

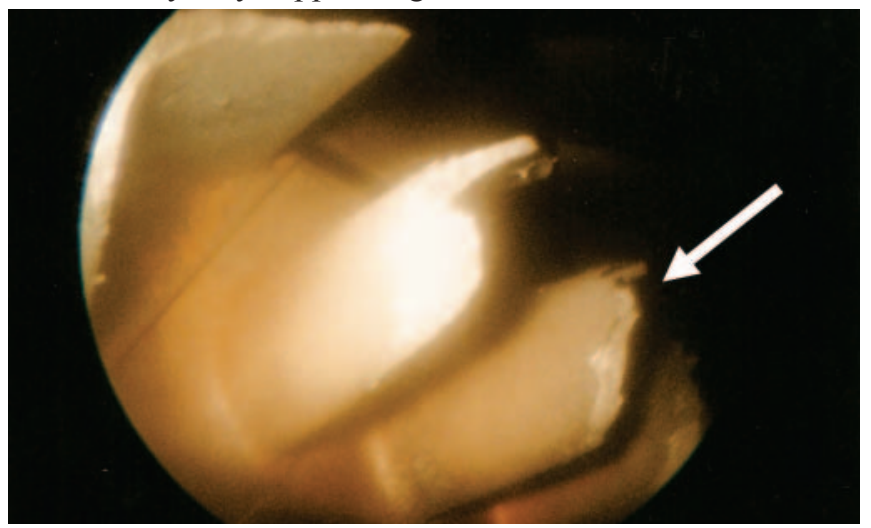

Fig. 2. Burnt-off tips of HP turbine rotor blades (acc. endoscopic examination)

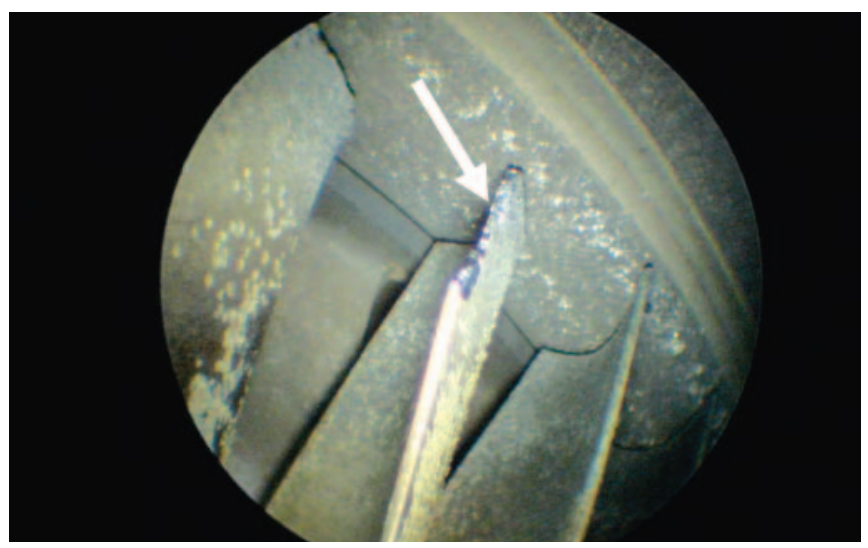

Fig. 3. Burnt-off tips of HP turbine rotor blades (acc. endoscopic examination)

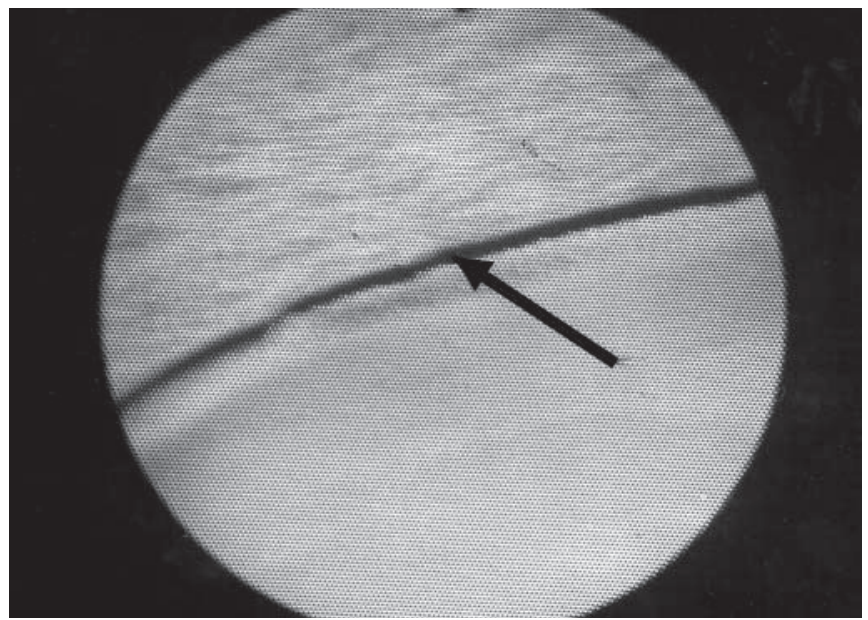

Fig. 4. Increased tip clearance of HP turbine blade with visible traces of seizing in engine body (acc. endoscopic examination) 

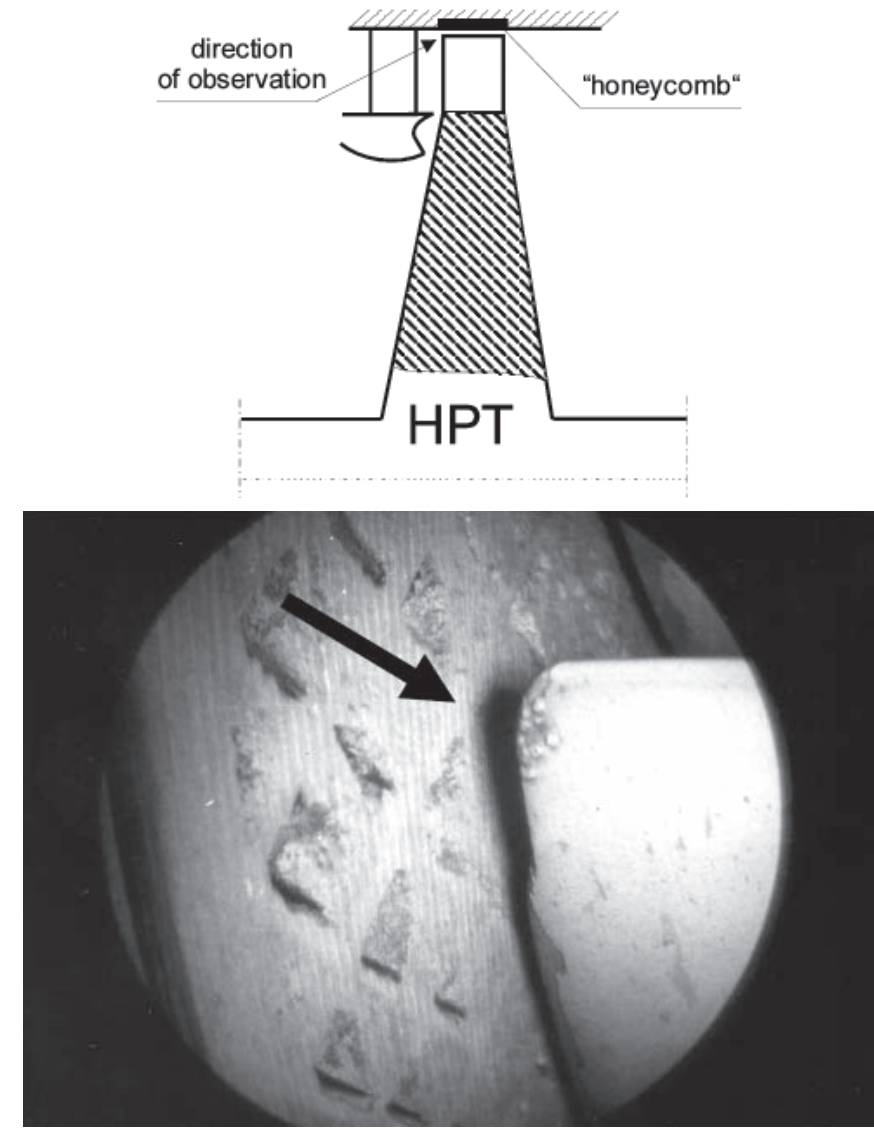

Fig. 5. Wear of sealing of HP turbine (HPT) rotor blades due to their seizing in engine body (acc. endoscopic examination)

It usually results in an intensive wear of body sealing of ,honeycomb” type (Fig. 5), that in consequence leads to significant increasing the clearance of rotor blades of turbine and dropping its efficiency even by $10 \%$ [13]. It impairs efficient performance of entire engine because, as a result of increased radial clearance of HP turbine, character of distribution, to successive turbine stages, of disposed enthalpy drop becomes changed. The largest power drop occurs at the last turbine stages, i.e. engine propulsion turbine $[12,13]$.

Another hazard to engine reliability, which results from rotor seizing in engine body, consists in possible cracking the compressor body, Fig. 6. The presented failure has been identified during endoscopic examination of a GTU6a singleshaft engine (of block structure) driving ship electric generating set. Compressor's body was made of 40HNMACr-Ni low-alloy steel of a higher metallugical purity. The situation occurred as a result of immediate switching-off the engine from operation under nominal load and passing over the cooling phase under idle running. Such decision of operators resulted from a fire observed in exhaust gas channel and entering the engine into unsteady operation range.After that the engine was dismounted and sent to its producer Repair of the body consisted in vacuum electron-beam welding the crack.

On the basis of the character of the appeared failure of the compressor body it can be concluded that the initial cause of the crack was a material defect, e.g. presence of sulfides at place of fracture. In ef fect of action of dynamic loads the fatigue fracture propagating just from the edge of the material defect, was initiated. As a result of rotor seizing in the compressor body in the temperature of about $700-800 \mathrm{~K}$, further propagation of the gap took place in the form of cleavage fractureAs the body was cooled more fast than the rotor the gap became separated mainly due to tensile forces (axial ones) with an influence of shear forces.
Designers of gas turbine engines take into account possible stopping the engine working under high load with passing over the cooling phase under idle-running. It is covered by manufacturer's testing program. Therefore the seizing of rotor units in engine body should not happen at all. However in the described case the engine immediate stopping was preceded by its unsteady work when a flash-back towards engine intake took place causing an inadmissible, very intensive rise of compressor material temperature much over its permissible value of $52 \mathrm{~K}$, determined by the manufacturer [15].

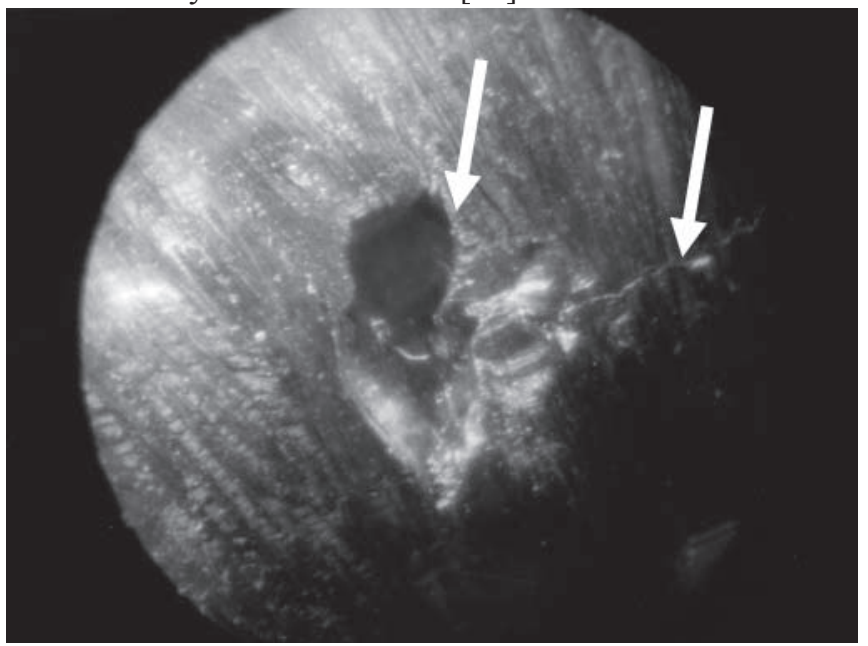

Fig. 6. Internal surface of GTU6a turbine engine compressor body, showing a fatigue fracture (acc. endoscopic examination)

The presented examples, despite their immediate destructive consequences to the engine's reliability, had also secondary consequences to its durability . During every load change, deformations and thermal stress changes of engine structural elements took place. In elevated temperatures they exceed material yield point and cause plastic compression-tension deformations at every heating-cooling cycle of the material. It turns out that even after a small number of such cycles the material surface cracking of deformed elements can happen, which, while propagating into their structure, can lead to dangerous breaking-off a fragment of the structure. This is an especially hazardous defect in the case of combustion chamber flame tubes, Fig. 7.There are known initial causes of an aircraft crash of tragic consequences where due to low-cycle fatigue of flame tube material of one of the engines fatigue cracks in its structure occurred. During start-up of the engine a relatively large metallic fragment was broken out of it. The fragment protruded engine casing and wing sheeting and caused fuel to leak and in consequence a violent fire to break in the rear part of the fuselage, that took the toll of 60 persons [acc. Discovery Science].

If low-cycle fatigue characteristics of a structural material are known it can be possible to easily determine a number of cycles after which surface cracking may happen, depending on a single amplitude value of the strain $\varepsilon$ which occurs during one heating-cooling cycle of the material operation, Fig. 8.

From the numerical data given by the fatigue characteristics the conclusion can be made that if the engine, for example an UGT3000 Zorya engine, has to be started $2 \div 3$ thou times during its life-time determined to be 12 years equivalent to 4 thou working hours, then one-sided deformations of the material (short-range local strain) should not exceed $0.2 \div 0.3 \%$, at each start-up, [15].

Stress concentration occurring in places of significant curvature changes of structural element outer surfaces (i.e. at notches) is conductive to local strains and fatigue fracture generation. Hence they appear mainly in necks of load-carrying 

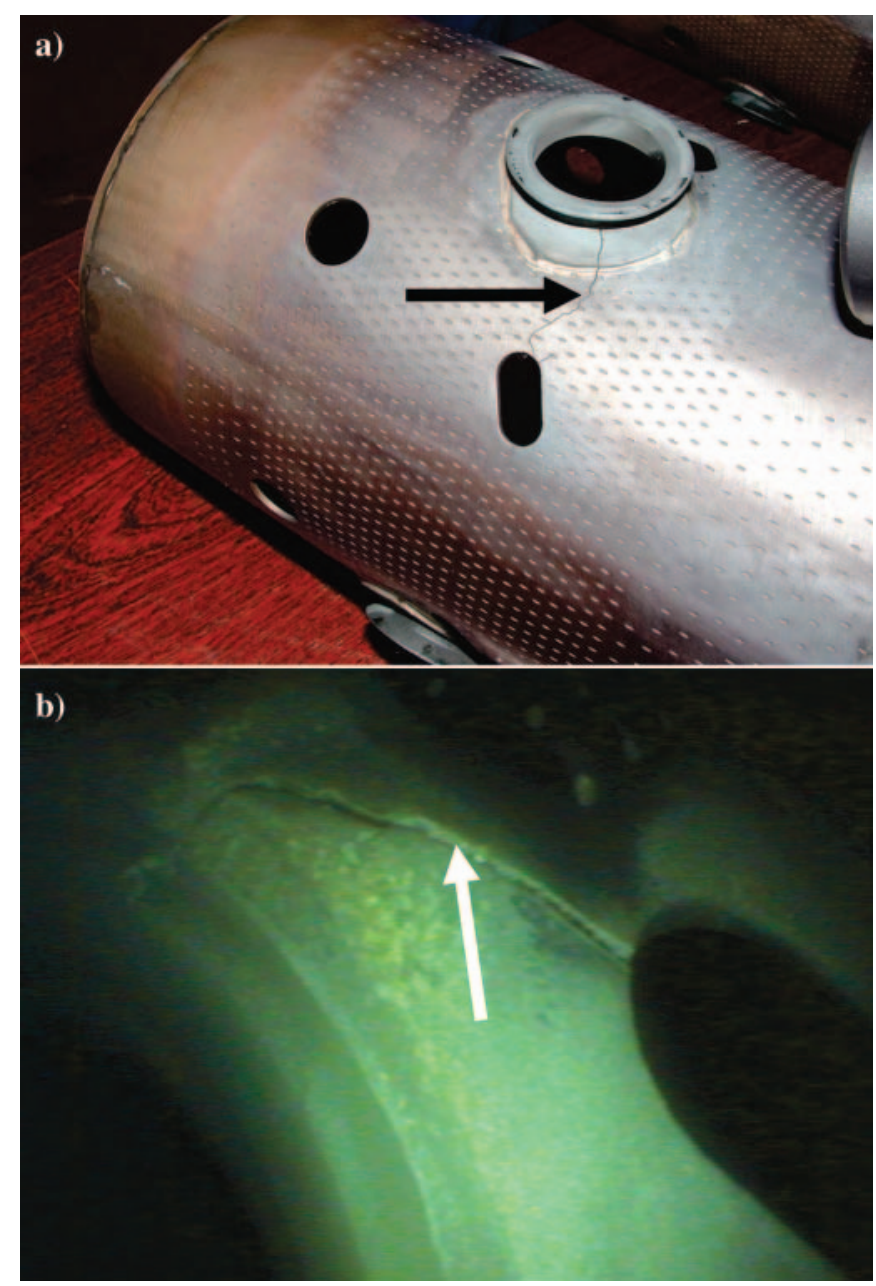

Fig. 7. Low-cycle fatigue fracture of flame tube of turbine engine combustion chamber: a) picture recorded just after the engine's dismounting; $\boldsymbol{b}$ ) picture obtained by endoscopic examination

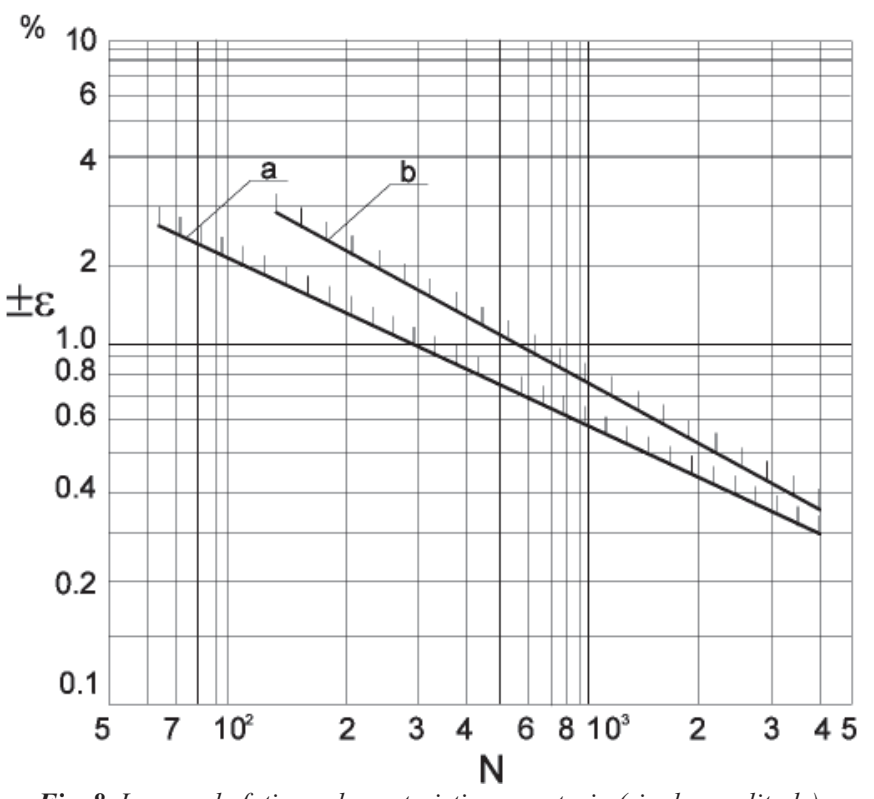

Fig. 8. Low-cycle fatigue characteristics: $\boldsymbol{\varepsilon}$ - strain (single amplitude),

$\boldsymbol{N}$-number of cycles (heating - cooling), $\boldsymbol{a}, \boldsymbol{b}$-fatigue limit (shown for two different materials)

disks of rotors, in places of the greatest diameter changes, close to openings and gaps of combustion chamber flame tubes as well as in neighborhood of significant changes of profiled cross-sections of internal shell bodies, Fig. 9.
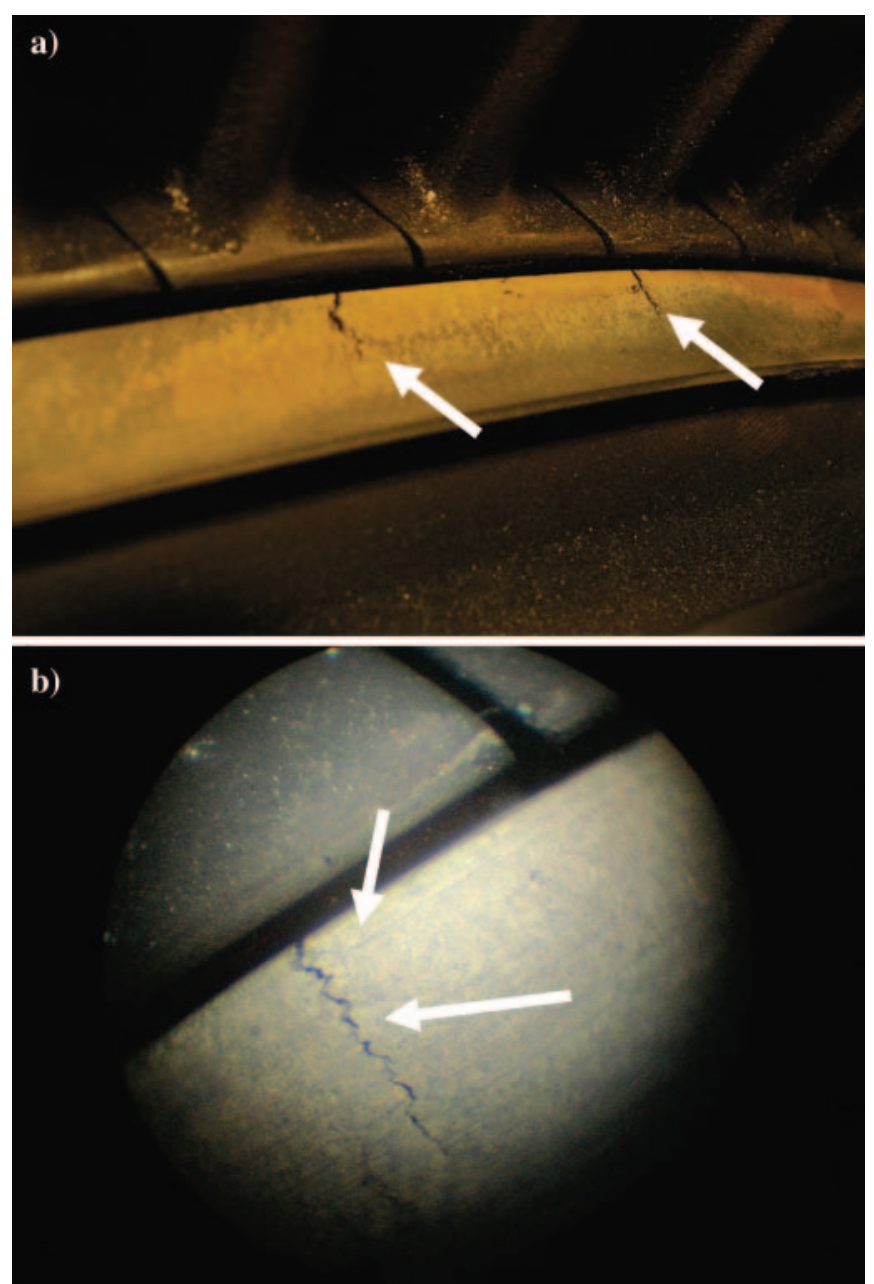

Fig. 9. Low-cycle fatigue fracture on internal body surface, under HP turbine guide vanes of a Zorya UGT3000 engine: a) picture recorded just after the engine's dismounting; b) picture obtained by endoscopic examination.

\section{CONCLUSIONS}

- Crucial diagnostic problem of gas turbine engines is to be able to early detect and correctly identify initial failures of structural elements of engine flow part during early phase of their development.

- While analyzing the research results presented in this paper it seems impossible to overestimate importance of new possibilities introduced, to the aspect in question, by more and more dynamically developing endoscopic methods.

- On the basis of available statistical data as well as results of the author's research it can be concluded that in present about $60 \%$ of all recorded failures of flow part of turbine engines is detected by means of endoscopic methods, which are also identified by other diagnostic methods.

- However in the case of fatigue failures endoscopy effectiveness is even higher, provided the diagnosing personnel is well experienced and possesses deep knowledge on probable places of occurrence and characteristic features of surface defects which have been so far happened in engines of given type series. 


\section{BIBLIOGRAPHY}

1. Boliński B., Stelmaszczyk Z.: Aircraft drives. Operation of turbine engines (in Polish). WKit (Traffic and Telecommunication Publishers), Warsaw 1981

2. Cohen H., Rogers G.F.C., Saravanamuttor H.I.H.: Gas turbine theory. Longman Scientific \& Technical, New York 1987

3. Dzierżanowski P. et al.: Aircraft drives. Turbine propeller and helicopter engines (in Polish). WKiE, (Traffic and Telecommunication Publishers), Warsaw 1985

4. Kocańda S., Szala J.: Background of fatigue calculations (in Polish). PWN(State Scientific Publishing House), Warsaw 1985

5. Kocańda S.: Fatigue fracture of metals (in Polish). WNT (Scientific Engineering Publishers), Warsaw 1985

6. Korczewski Z:: A method for diagnosing flow part of ship gas turbine engine in service (in Polish). Doctor thesis. AMW(Polish Naval Academy), Gdynia 1992

7. Korczewski Z.: Diagnostic-purpose identification of gasdynamic processes in gas turbine engine compressor unit (in Polish). AMW (Polish Naval Academy), Gdynia 1999

8. Korczewski Z.: Endoscopy of ship engines (in Polish). AMW (Polish Naval Academy), Gdynia 2008

9. Lewitowicz J., Wieczorek O. Żyluk A.: Damages of structural components and units of a gas turbine engine. Journal of Polish CIMAC, Diagnosis, Reliability and Safety, Vol. 4, No. 2/ 2009

10. NeimitzA.: Fracture mechanics (in Polish). PWN(State Scientific Publishing House), Warsaw 1998
11. RządkowskiR.: Flutter of turbine rotor blades in inviscid flow. AMW (Polish Naval Academy), Gdynia 2004

12. SzczecińskiS.: Aircraft two-rotor and two-flow turbine engines (in Polish). WKiŁ (Traffic and Telecommunication Publishers), Warsaw 1971

13. SzczecińskiS.: Study on tip clearance of rotor units of aircraft turbine engines, taken as a design and operation parameter (in Polish). Appendix to Bulletin of WAT(Military Technical Academy), No.4 (248), Warsaw 1973

14. SoaresC.: Gas turbines. A handbook of air, land and sea application. Butterworth-Heinemann, Elsevier Inc. 2008

15.Technical and operational documentation of ship gas turbine engines of the types: GTU6a, DE59, UGT Zorya, LM2500 General Electric.

16. Reports on diagnostic tests of piston and turbine combustion engines used on Polish Navy ships (in Polish). Research projects, AMW (Polish Naval Academy), Gdynia $1992 \div 2008$.

\section{CONTACT WITH THE AUTHOR}

Zbigniew Korczewski, Assoc. Prof. Faculty of Ocean Engineering and Ship Technology

Gdansk University of Technology Narutowicza 11/12 80-233 Gdansk, POLAND e-mail : sek4oce@pg.gda.pl 